\title{
Investigation on the performance of a prototype of thermo-electric generation with heat pipe-heat sink
}

\author{
Ali Elghool ${ }^{1,2}$, Firdaus Basrawi ${ }^{1}$, Hassan Ibrahim ${ }^{l}$ and Thamir Ibrahim ${ }^{l}$ \\ ${ }^{1}$ Energy Sustainability Focus Group, Faculty of Mechanical Engineering, Universiti Malaysia Pahang \\ 26600 Pekan, Pahang, Malaysia \\ ${ }^{2}$ Higher institute of sciences and technology/Gharian / Libya
}

\begin{abstract}
A significant problem in thermo-electric generators is the thermal design of the heat sink because it affects the performance of thermoelectric modules. As compared to conventional cooling systems, heat pipe heat sink have numerous advantages. Some of these advantages are: high heat-transfer rates; absence of moving parts and lack of auxiliary consumption (passive system). This paper presents the analysis of power generation using the combination of heat pipes and thermo-electric generators. The aim is to improve power output by an appropriate design of the heat sink. The average geometrical parameters of heat sink (fin height, fin space and fin thickness) were obtained from data collected from previous studies closely similar to this prototype. The prototype was tested and the temperature, voltage and current data were collected. All data were recorded by using a temperature data recorder, power meter and multimeter. It was found that the highest maximum power output was 1.925 watts at a temperature difference of $85^{\circ} \mathrm{C}$. However, the prototype did not achieve the maximum output expected. This was a result of limitation of TEG model (where only one TEG was used) and the limitation of the performance of the prototype. The prototype successfully generated enough power to charge a cell phone and laptop when connected to two or three TEGs. Moreover the heat pipe heat sink needs optimization to meet the design output from the manufacturer of the TEG at hot side temperature and cold side temperature.
\end{abstract}

\section{Introduction}

Energy demand will keep increasing with the rapid development of technologies and industrialization. The current economy relies heavily on fossil fuels. Progress in the industrial sector and adoption of new technologies have further strengthened reliance on this fuel source. However, fossil fuels have inherent limitations since their reserves are increasingly depleting. In addition, there are a number of environmental issues related to fossil fuels production and utilization at both local and global scales. Furthermore, a significant portion of energy from fossil fuels is wasted during the transformation process and use. Owing to the issues related to fossil fuels, energy experts around the world have expressed concerns about 
the future of energy generation[1,2]. Thermo-electric generator (TEG) has shown to offer a dependable and simpler way of thermo-electric energy conversion. Advantages of a TEG module include lack of moving parts, environmental safety, and silent operation. This generator can also be controlled in a seamless and accurate manner. Researchers have shown increased interest using thermo-electric technology in improving waste recovery efficiency over the last three decades. This has been made possible using a variety of heat-producing processes[3]. According to the Web of Science database, annual publications in thermoelectric technology had increased in the last 15 years from 500 to as high as 2000 [4].

However, low efficiency in conversion has remained to be a primary challenge facing thermo-electric power production[5-7]. TEG heat exchanger's (heat sink) lack of design is one reason that causes shortcoming in the conversion efficiency of the TEG. These days, there is a profound research in heat sinks with heat pipes that enhances heat sinks significantly more, with a small temperature drop, because of the utilization of the latent heat of an internal fluid[8]. Heat pipe heat sink (HPHS) is the most suitable heat exchanger for the medium temperature range below $300^{\circ} \mathrm{C}$ with TEG (Energy Efficiency Guide for Industry in Asia)[9] which is the authors' work scope. Heat pipe has two ends, where one end works as evaporator placed on the TEG cold side to absorb the heat. This absorbed heat evaporates the fluid inside, which then flows to another end which works as condenser. At this end, it condensates, as it releases the heat to the ambient with the help of fins attached to it, and the fluid returns back to the evaporator. Thermo-electric generators have recently been investigated as a method of electricity generation with waste heat as heat source. Araiz.M [10] had studied thermo-syphons with phase change in thermo-electric generators in a wasteheat recovery application, stating that including thermo-syphons on the cold side of the generators improves the net thermo-electric production by $36 \%$ as compared to that obtained with finned dissipaters under forced convection.

Martinez, A[11], studied the combination of heat pipe exchangers and thermo-electric selfcooling and demonstrated its applicability to the cooling of power electronics. Experimental tests indicate that source-to-ambient thermal resistance reduces by around 30\% when thermoelectric self-cooling system is installed, compared to that of the heat pipe exchanger under natural convection. Geometrical parameters of heat sink with heat pipe (fin height, fin space and fin thickness) have not been studied in previous work. In this paper, the main focus is to develop and test a prototype of thermo-electric-based power generator. The aim is to experimentally study the geometry of heat sink with heat pipe (fin height, fin space and fin thickness). The average geometrical size of heat sink was obtained depending on data collected from previous studies that were closely similar with this prototype.

\section{Methodology}

\subsection{Description of the proposed system}

Fig. 1 shows the design of the TEG prototype - one TEG was used in this experiment. The TEG hot side was placed on a heater to simulate the source of heat. Heat was transferred from the hot side to the cold side of the TEG. The cold side was attached to the aluminium block, 


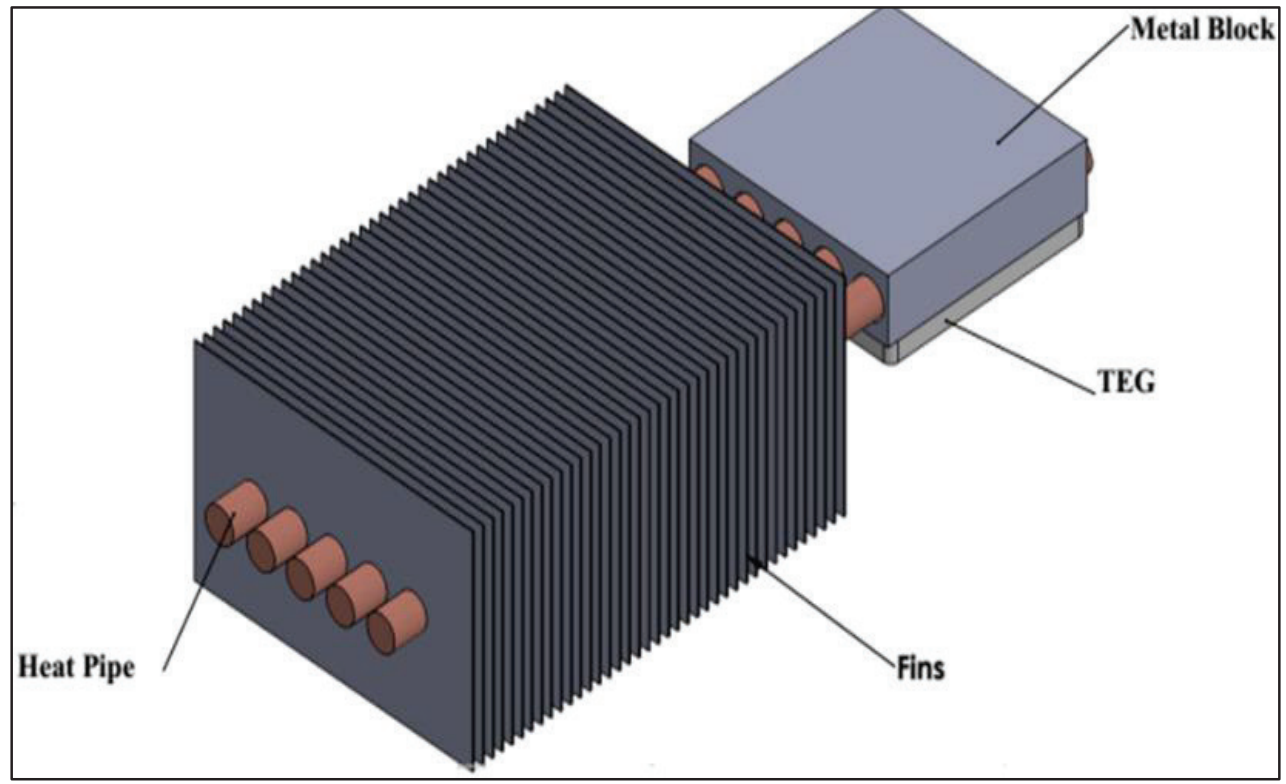

Figure 1. A schematic of the combined heat pipe- heat sink with thermoelectric generator.

where five heat pipes of 50W each were inserted in it. The TEG did not need any thermal paste as it was built with graphite foil as thermal interface material. On the other side of the heat pipes, there were fins to dissipate heat to the environment. Thirty-three aluminium (A15052) were bounded mechanically on the heat pipes. The dimensions of each fin were $120 \times 80 \times 0.5 \mathrm{~mm}$. Interference fit method was used to assemble the fins to the heat pipes (also called press fit or friction fit), in which the fins had holes that were slightly smaller than the diameter of the heat pipe. By pressing the fins onto the heat pipes with pressure, the heat pipe and the fins were tightly assembled. When the temperature increased during working condition, thermal expansion of the fins and heat pipes will made the assembly even more secure. Table 1 describes the TEG specifications that were used in this study. Five pieces of copper heat pipes with $200 \mathrm{~mm}$ long and $8 \mathrm{~mm}$ outer diameter were used to dissipate heat from TEG cold side. When the hot side was supplied with $300^{\circ} \mathrm{C}$ of heat, whereas the cold side was maintained at $30^{\circ} \mathrm{C}$, the TEG had the capability to generate $7.2 \mathrm{~V}, 3.0 \mathrm{amps}$, hence generates $21.6 \mathrm{~W}$. This is the ideal case when the device is designed by the manufacturer. The heat pipes have fibre wick structure with heat flux of $50 \mathrm{~W}$. Therefore, $250 \mathrm{~W}$ of heat can be transferred through the five heat pipes that were used.

\subsection{Testing and data collection}

Testing of the prototype was carried out as shown in Fig. 2. An electric heater was used as the heat source and a variable resistance was connected as electrical load. The TEG would deliver the maximum power output (Power = Volts x Amps) when the Load resistance equals the TEG internal resistance. (R of Load = R of TEG) by using the chart of "TEG resistance" form the manufacturer to determine the TEG's resistance at the temperatures that will provide it. If the TEG internal resistance could not match the load precisely, then the load resistance was made slightly higher than the TEG resistance rather than lower. The data collected were temperature, voltage and current. For recording of temperature, a 12-Channel Temperature 
Recorder, BTM-4208SD was used. Thermocouples were placed at the hot side and cold side of the TEG. The date were recorded with intervals of 60 seconds for 1420 seconds (approximately 23 minutes). For voltage, it could be taken for both open and close circuits. But for the current, the circuit had to be loaded so the current can be measured. From the voltage and current measured, power (W) can be obtained by a conventional equation as shown below.

$$
\mathrm{P}=\mathrm{I} \times \mathrm{V}
$$

Where I is current (amp), and V is voltage (Volt). The fins were cooled down by natural convection, with the average air speed about $1.6 \mathrm{~m} / \mathrm{s}$. It was simulated in the laboratory through a fan. Consequently, the cooling method was considered as passive. The average air velocity was obtained from data collected from previous studies at UMP.

Table 1. Thermoelectric Specifications

\begin{tabular}{|c|c|c|c|c|l|}
\hline $\begin{array}{c}\text { Maximum Hot } \\
\text { side temperature } \\
\left({ }^{\circ} \mathrm{C}\right)\end{array}$ & $\begin{array}{c}\text { Maximum cold } \\
\text { side temperature } \\
\left({ }^{\circ} \mathrm{C}\right)\end{array}$ & $\begin{array}{c}\text { Dimensions } \\
(\mathrm{mm})\end{array}$ & $\begin{array}{c}\text { Voltage } \\
(\mathrm{V})\end{array}$ & $\begin{array}{c}\text { Current } \\
(\mathrm{A})\end{array}$ & Power $(\mathrm{W})$ \\
\hline 320 & 180 & $56 \times 56 \times 4.45$ & 7.2 & 3.0 & 21.6 \\
\hline
\end{tabular}

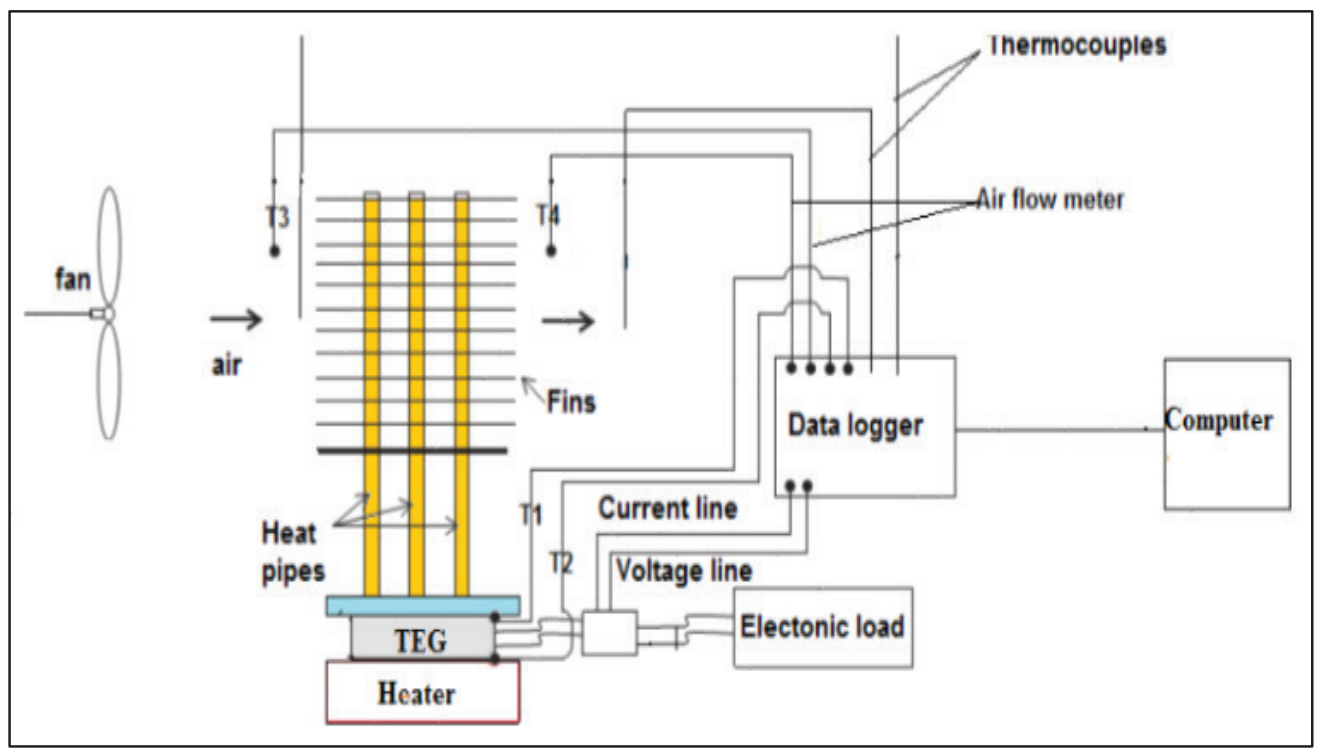

Figure 2. The schematic of the experimental setup

\section{Results and discussion}

Fig. 3, 4, 5 and 6 show results for voltage, current, power output and temperature difference, respectively. As shown in the figures, current and voltage show similar trend. The maximum voltage was $5.5 \mathrm{~V}$, and current was $0.35 \mathrm{~A}$. The maximum power obtained was $1.925 \mathrm{~W}$ as shown in Fig. 5. Subsequently, by connecting two or three TEGs to form a model, power output will double enough to run a mobile phone and laptop. The maximum power output of 
$1.925 \mathrm{~W}$ is much less than what was expected, which is $15 \mathrm{~W}$ as per design from the manufacturer of TEG at hot side temperature $250^{\circ} \mathrm{C}$ cold side temperature $25^{\circ} \mathrm{C}$. Fig. 6 shows the temperature difference between hot and cold sides of the TEG. It can be seen that the temperature difference increased constantly until $1200 \mathrm{~s}$, then the temperature was almost constant which indicates that the operation has reached its steady-state.

It was found that the highest temperature difference was $83{ }^{\circ} \mathrm{C}$, For a low temperature difference, between hot side of TEG and cold side, the main cause was perhaps due to lack of heat sink design because it was observed that the temperature at the fins side also reached almost $100^{\circ} \mathrm{C}$ during the end of the testing. Thus, improvement in the heat sink is needed for better power output. As for the shortage of maximum power output, only one TEG was used due to the limitation of the performance of the heat pipe heat sink. For the power output limitation two or three TEGs should be connected to form one module. It can be concluded that the prototype successfully generated enough power to charge a cell phone and laptop with a multiple connection of two or three TEGs. Moreover heat pipe heat sink needs optimization to approach as close as possible from the ideal situation of the manufacturer's design of TEG, namely; with $250^{\circ} \mathrm{C}$ hot side and $25^{\circ} \mathrm{C}$ cold side, with the TEG generating $15 \mathrm{~W}$.

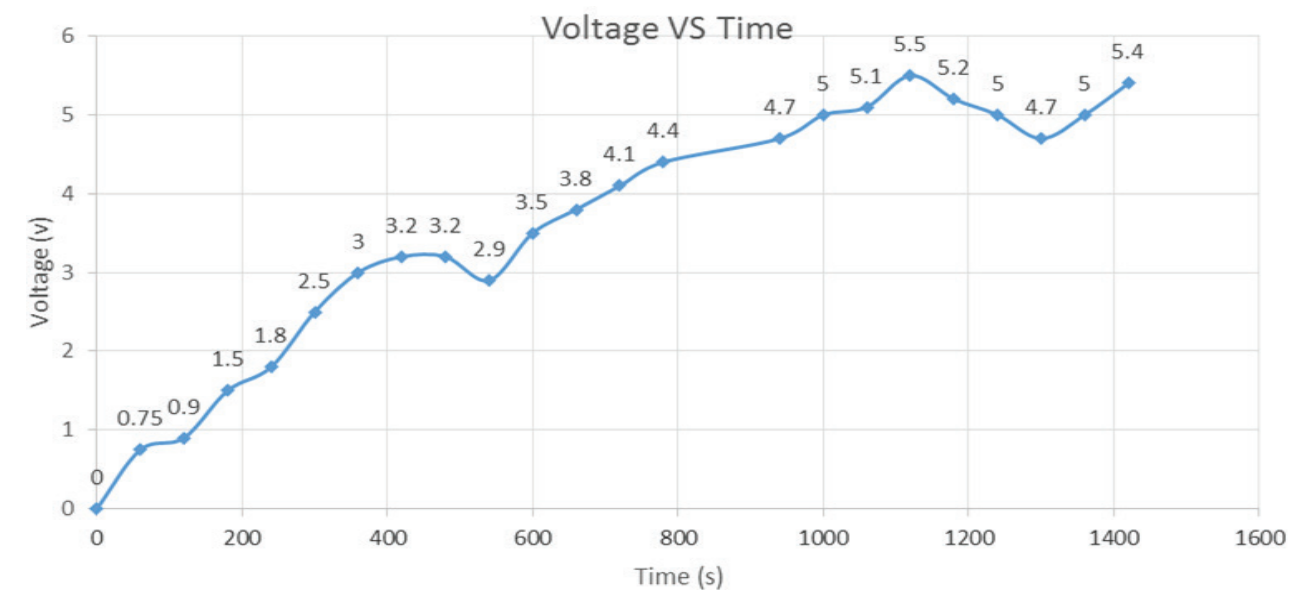

Figure 3. Chart for voltage vs time (S).

\section{Conclusion}

A prototype of thermo-electric generator (TEG) based power generation system was tested. The prototype consisted of a heat source, one TEG connected with heat pipe heat sink (passive system). It was found that the highest temperature difference was $83^{\circ} \mathrm{C}$, maximum voltage was $5.5 \mathrm{~V}$, maximum current was $0.35 \mathrm{~A}$ and maximum power obtained was $1.925 \mathrm{~W}$. The maximum power output of $1.925 \mathrm{~W}$ was much less than what was expected, which was 15 W as per design from the manufacturer of the TEG with hot side temperature $250^{\circ} \mathrm{C}$ and cold side temperature $25^{\circ} \mathrm{C}$. This was a result of limitation of maximum power output (only one TEG was used) and the limitation of the performance of the heat pipe heat sink. For the power output limitation two or three TEG should be connected to form one module. For a low temperature difference between hot side of TEG and cold side, the main cause was possibly due to lack of proper heat sink design. Heat pipe heat sink needs optimization to meet the 
design output from the manufacturer of the TEG at hot side temperature and cold side temperature.

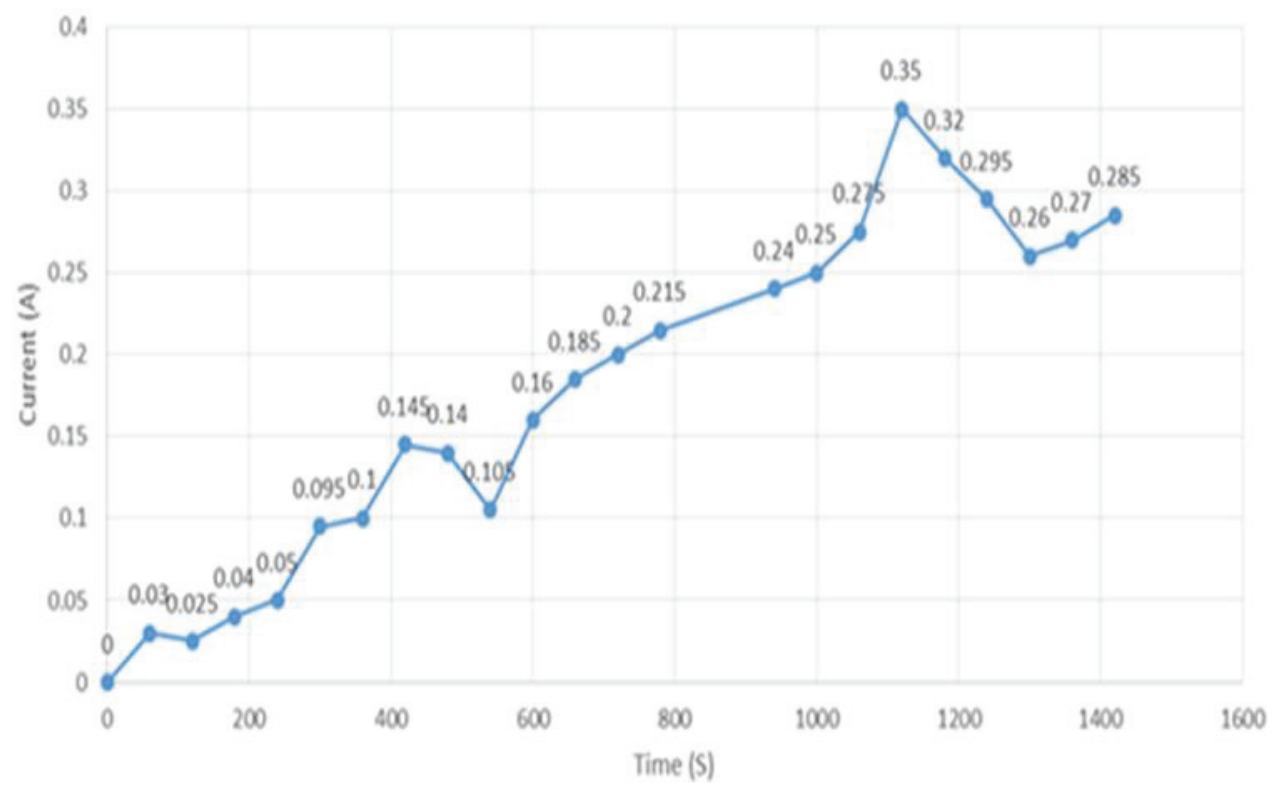

Figure 4. Chart for current vs time (S).

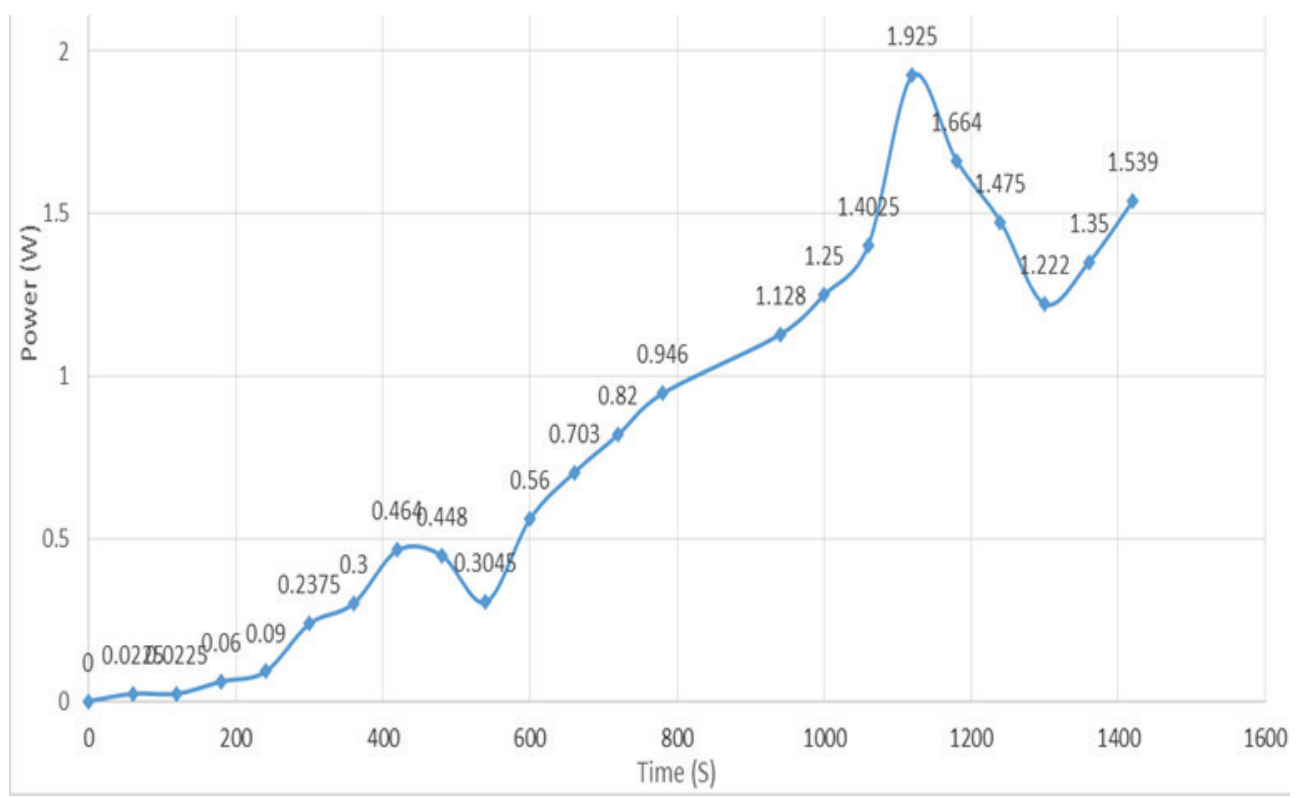

Figure 5. Chart for power vs time (S). 


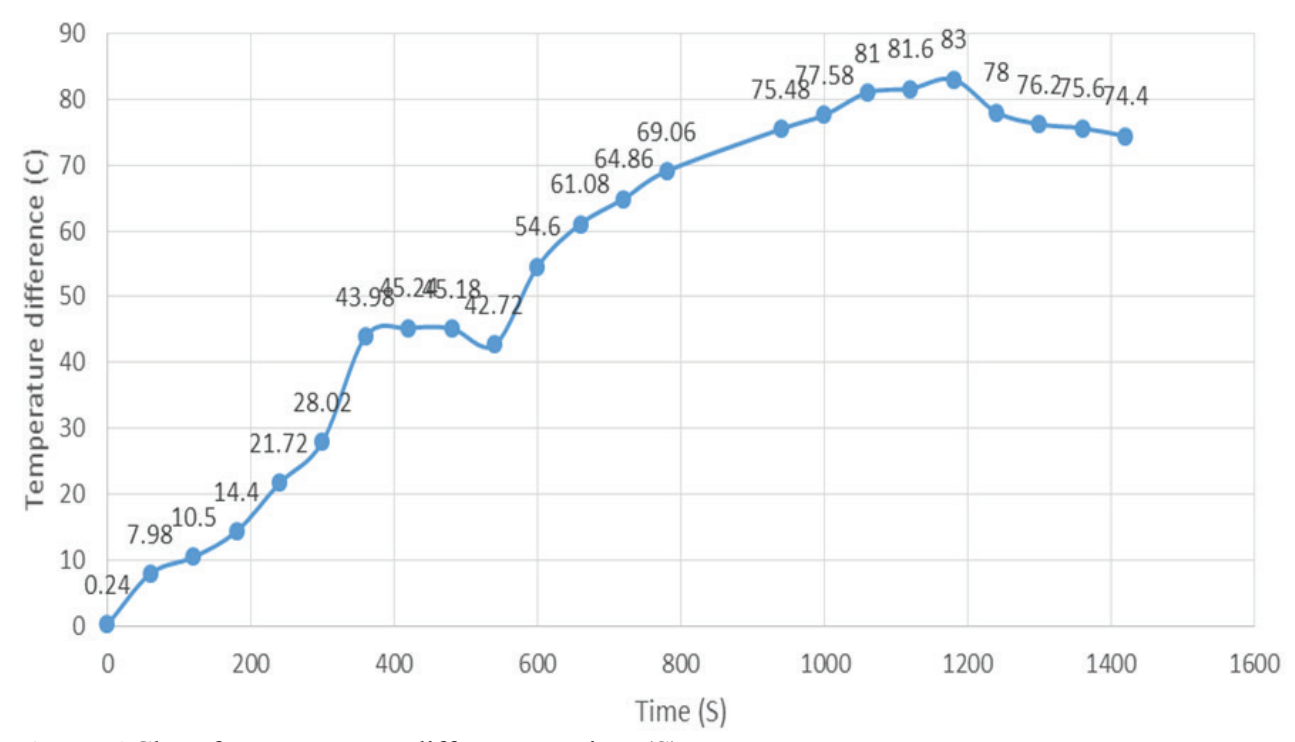

Figure 6.Chart for temperature difference vs time (S)

\section{Acknowledgement}

The authors gratefully acknowledge Universiti Malaysia Pahang for providing the internal grant under RDU160310.

\section{References}

1. A.Elghool, enrg.con.M., (2017). 134: p. 260-277.

2. K.Yazawa, Y.R.K., and A. Shakouri, Appl. En, (2013). 109: p. 1-9.

3. K.Yazawa, enrg.con.M., (2014). 84: p. 244-252.

4. W.Liu, Acta .M, (2015). 87: p. 357-376.

5. C.Gayner, K.K., (2016). 83: p. 330-382.

6. $\quad$ H.Wu., Nano .E, (2015). 13: p. 626-650.

7. M.Elsheikh, Ren,Sust. Ene. R, (2104). 30: p. 337-355.

8. H.Shabgard., Inter. Jour.of Heat and Mass Trans., (2015). 98: p. 138158.

9. M.Remeli., enrg.conv.M. (2015). 91: p. 110-119.

10. M.Araiz, enrg.con.M., (2017). 137: p. .155-164.

11. A.Martinez, Energy., (2016). 112: p. 1-7. 